\title{
Light Wavelength and Power Quality Characteristics of CFL and LED Lamps under Different Voltage Harmonic Levels
}

\author{
Kamran Dawood*‡, Bora Alboyaci*, Mehlika Sengul**, Ibrahim Gursu Tekdemir* \\ * Department of Electrical Engineering, Kocaeli University, Umuttepe Campus 41380 Izmit, Kocaeli, Turkey \\ ** Civil Aviation College, Arslanbey Yerleskesi 41285 Kartepe, Kocaeli, Turkey \\ (kamransdaud@yahoo.com, alboyaci@kocaeli.edu.tr, mehlika@kocaeli.edu.tr, gursu.tekdemir@kocaeli.edu.tr)
}

\footnotetext{
ॠCorresponding Author; Kamran Dawood, Department of Electrical Engineering, Kocaeli University, Umuttepe Campus 41380 Izmit, Kocaeli, Turkey, Tel: +905060663676, kamransdaud@yahoo.com
}

Received: 01.03.2017 Accepted: 04.04.2017

\begin{abstract}
Conventional light sources are less efficient as compared to the light emitting diode and compact fluorescent lamps. Conventional incandescent filament lamps are resistive and therefore do not depend on power quality parameters. In the electric power system, nonlinear loads are increasing rapidly and the high content of harmonic due to the nonlinear loads cannot be neglected. Harmonic generation from the light emitting diode and the compact fluorescent lamp is one of the main problems for power quality. In this study, the light efficiency and electrical characteristics of the light emitting diode lamps and compact fluorescent lamps are evaluated under various voltage harmonic levels. The results show that light emitting diode, produces more harmonics as compared to the compact fluorescent lamps, with the increase of the voltage harmonic distortion from $0.7 \%$ to $3.52 \%$ in the light emitting diode, current harmonic increased from $140 \%$ to $192 \%$. The results also show that increase in voltage harmonic distortion just not only increase current harmonics distortion but also affect the light wavelength of the lamp.
\end{abstract}

Keywords LED lamps, CFL, Total harmonic distortion, Light intensity, Power quality.

\section{Nomenclatures}

LED Light Emitting Diode

CFL Compact Fluorescent Lamp

I Luminous Intensity

W Watt

THD Total Harmonic Distortion

RMS Root Mean Square

$\mathrm{V}_{\mathrm{H}} \quad$ RMS Voltage of the hth Harmonic

$\mathrm{V}_{1} \quad$ RMS Voltage of the fundamental Harmonic

$\mathrm{I}_{\mathrm{H}} \quad$ RMS Current of the hth Harmonic

$\mathrm{I}_{1} \quad$ RMS Current of the fundamental Harmonic

$\mathrm{THD}_{\mathrm{V}}$ Total harmonic distortion of voltage (\%)

$\mathrm{THD}_{\mathrm{I}}$ Total harmonic distortion of current (\%)

\section{Introduction}

Since last few years energy saving lamps, LED lamps and CFLs are replacing incandescent light bulb due to the power saving. The average efficiency of the standard incandescent bulbs is about 2.2\% [1] almost 97.8\% of the total energy is converted into heat. Many governments have introduced directives to replace the incandescent light bulbs with energy saving lamps, such as CFLs and LED lamps [24].

Several studies have been conducted on the highly distorted current of the CFL lamps [5-9]. LED lamps also produce highly distorted current and many different studies have been conducted on the electrical characteristics of LED [9-10].

There are many advantages of using CFL and LED lamps over using of incandescent bulbs. Luminous efficacy 
of the LED lamps and CFLs are high as compared to the luminous efficacy of the incandescent bulbs. Efficacy of the typical incandescent bulb is about 16 lumens per watt and efficacy of the CFL and white LED lamps are $60 \mathrm{~lm} / \mathrm{W}$ and $150 \mathrm{~lm} / \mathrm{W}$ respectively [11] But the main concern about LED lamps and CFLs are the generation of current harmonic distortion. Different types of LED lamps and CFLs generate different levels of the harmonic distortion. As nonlinear loads, LED lamps produce highly distorted currents [12]. LED lamps and CFLs require less active power as compared to the incandescent bulb; however, a large number of the consumer using CFLs and LED lamps in one location may give rise to significant power problems [13]. Over the years, many types of researches are also conducted on the internal ballast circuit and harmonic characters of the CFL and LED lamps [13-17].In this paper, CFLs and LED lamps are categorized on the colour temperature and colour type to analyze their light wavelength and electrical characteristics.

In this study, the light efficiency and electrical characteristics of the LED and CFL are evaluated under various voltage harmonic levels. Two CFLs of $23 \mathrm{~W}$ and two LED lamps of $18.7 \mathrm{~W}$ were used and all of the lamps have same luminous flux. To see the effect of colour temperature of armature hot and cold colour type lamps were used. CFLs and LED lamps were tested under different conditions i.e. without harmonic voltage and with different levels of harmonic voltages. The experiments were conducted to see the harmonic current and light intensity response of the CFLs and LED lamps. The experiment results were also compared with the IEC 61000-3-2.

\section{Basic Photometric Quantities}

Optical measurements techniques can be subdivided into photometry and radiometry. The main problem with photometry is that the determination of optical quantities is directly related to the sensitivity of the human eye. The measurement of energy per time emitted by the light source is commonly known as radiometry. Some photometric quantities are given below.

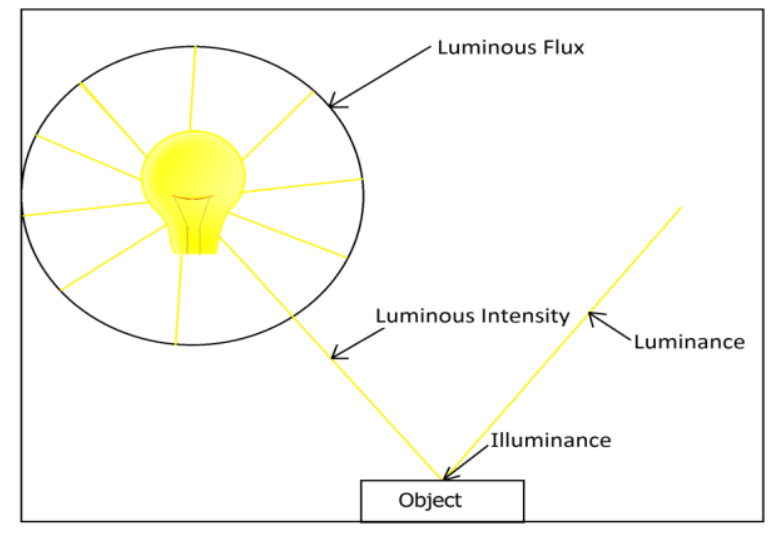

Fig. 1. Photometric Quantities.

\subsection{Luminous Intensity}

The luminous intensity is a photometric quantity, represents the light intensity of an optical source, as perceived by the human eye. The symbol of luminous intensity is I.

The S.I unit of luminous intensity is candela, it is defined as the luminous intensity of a light source emitting a monochromatic light having an optical power of (1/683) watt per steradian in a given direction at a wavelength of $555 \mathrm{~nm}$, that the source will emit one candela in the specified direction.

\subsection{Luminous Flux}

The quantity of the energy of the light emitted per second in all directions is known as luminous flux. Figure 2 shows the luminous efficiency function for both scotopic and photopic vision, it describes the average spectral sensitivity of human visual perception of brightness.

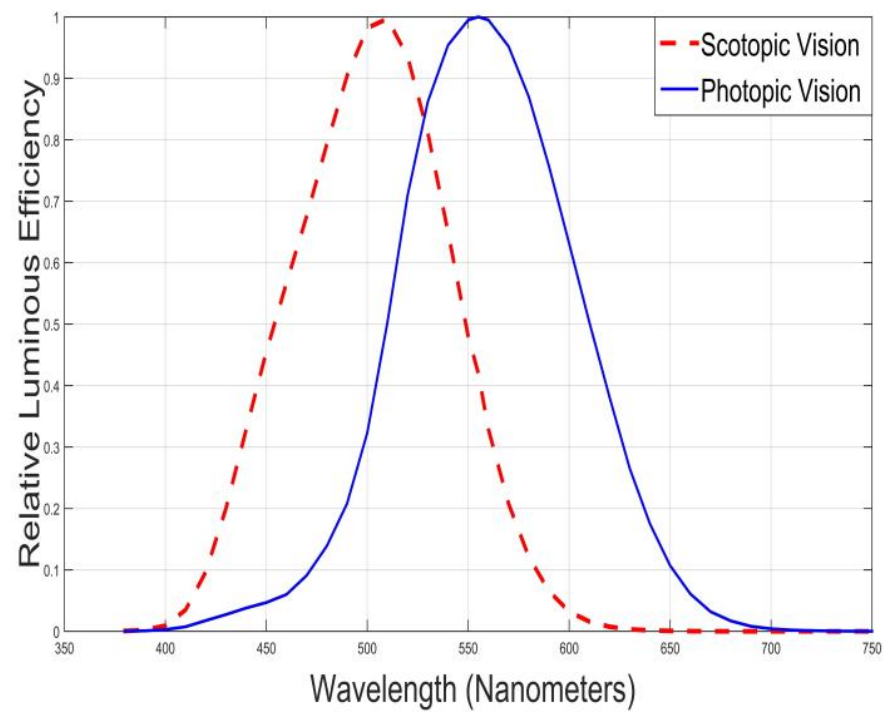

Fig. 2. Spectral sensitivity of the human eye.

Human eyes have different sensitivities within the spectrum with respect to the wavelength. Greenish-yellow light at a wavelength of $555 \mathrm{~nm}$ is most sensitive to the human eyes. SI unit of luminous flux is lumen ( $\mathrm{lm}$ ). Lumen is defined as the luminous power of a light source emitting a monochromatic light having the power of $(1 / 683)$ watt at a wavelength of $555 \mathrm{~nm}$. It defines that at the wavelength of $555 \mathrm{~nm}$, 1watt of radiant light is equal to 683 lumens.

\subsection{Luminous}

Luminous intensity per unit area of light traveling in a given direction is known as luminous. It is used to characterize the reflection and emission from particular area. The SI unit of luminous is candela per square meter $\left(\mathrm{cd} / \mathrm{m}^{2}\right)$.

\subsection{Illuminance}

The illuminance is the perpendicular component of the luminous flux that falls on the surface. S.I unit of illuminance is lux. Table 1 is showing illuminance for the different illuminance conditions. 
Table 1 Typical illuminance in different environments [18]

\begin{tabular}{|c|c|}
\hline Illumination condition & Illuminance [lux] \\
\hline Full moon & 1 \\
\hline Street lighting & 10 \\
\hline Home lighting & 30 to 300 \\
\hline Office desk lighting & 100 to 1000 \\
\hline Surgery lighting & 10000 \\
\hline Direct sunlight & 100000 \\
\hline
\end{tabular}

\section{Power Quality}

Power systems are operating in the range of $50-60 \mathrm{~Hz}$ Frequencies. However, sometimes loads create current and voltages with frequencies that are normally integer multiples of the fundamental frequency. These multiple integers of frequencies are known as power system harmonics and these frequencies are a form of electrical pollution. There are many studies conducted on the impact of CFL and LED lamps on the power quality [20-22]. Harmonics are normally added by the non-linear loads. Use of the semiconductor in the switching part of the electronic equipment is the main reason of non-linearity in the load. Some of the equipment causing harmonics are computers, TVs, printers, CFL bulbs, and motors [19].

The Total Harmonic Distortion (THD) is defined as the ratio of the RMS value of the waveform (without fundamental) and the RMS value of the fundamental. Total harmonic distortion of the voltage is defined by:

$$
[T H D]_{V}=\frac{\sqrt{\sum_{h=2}^{\infty} V_{h}^{2}}}{V_{1}}
$$

Total harmonic distortion of the current is defined by:

$[T H D]_{I}=\frac{\sqrt{\sum_{h=2}^{\infty} I_{h}^{2}}}{I_{1}}$

It is found that most of the new design of LEDs with lower power rating $(<25 \mathrm{~W}$ att) have a power factor $(\mathrm{PF})$ up to 0.6 and current total harmonic distortion (THDI) between 100-140 \% [13], [23].

IEC 61000-3-2 gives the limits for the equipment that draws the input current less than 16A per phase [24]. Lightning equipment harmonic emission is divided into two categories i.e. having active power up to $25 \mathrm{~W}$ and active power greater than $25 \mathrm{~W}$. Lightning equipment having active power up to $25 \mathrm{~W}$ must follow the one of the following condition [24].

In the first condition, $3^{\text {rd }}$ and $5^{\text {th }}$ Harmonic current should not be greater than $86 \%$ and $61 \%$ of the fundamental current respectively. According to the first condition, the maximum limit of the current total harmonic distortion is approximately $105 \%$.
According to the second condition, $3^{\text {rd }}$ harmonic should not be greater than $30 \%$ of the power factor. Detail of the second condition is given in Table 2 .

Table 2 Limits for lightning equipments $(\mathrm{P} \leq 25 \mathrm{~W})$

\begin{tabular}{|c|c|}
\hline Harmonics [h] & Percentage of fundamental \\
\hline 2 & 2 \\
\hline 3 & 30 x Power Factor \\
\hline 5 & 10 \\
\hline 7 & 7 \\
\hline 9 & 5 \\
\hline $11 \leq \mathrm{n} \leq 39$ (odd harmonics only) & 3 \\
\hline
\end{tabular}

\section{Experimental Setup}

This section illustrates the experimental setup and the experimental results of the current harmonic and performance of CFL and LED lamps.

A Tektronix DPO5034 digital oscilloscope ${ }^{3}$, Everfine spectrum coating integrating sphere ${ }^{2}$, Chroma programmable AC source $61704^{4}$, Newport optical spectrometer OSM-100 ${ }^{1}$ and two computers were used in the experimental setup as given in figure 3. Tektronix DPO5034 digital oscilloscope is used to find the current response of the lamps. Wavelength and light intensity of the lamps are measured from Newport optical spectrometer. Different levels of the voltage harmonics are generated from Chroma programmable AC source 61704. Technical data of the experimented CFLs and LED lamps are given in Table 3.

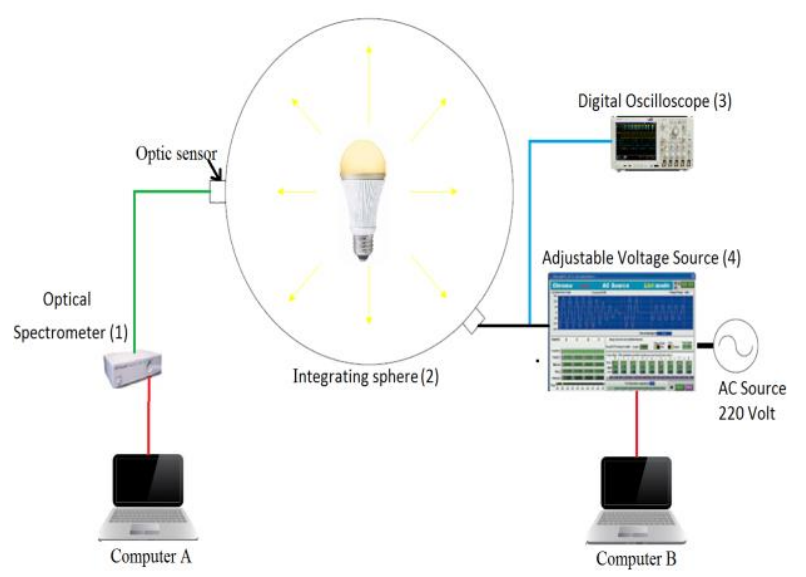

Fig. 3. Experimental Setup.

Table 3. Technical data of lamps

\begin{tabular}{|c|c|c|c|c|}
\hline Rated Value & CFL-1 & CFL-2 & LED-3 & LED-4 \\
\hline Nominal RMS Voltage & 220 & 220 & 220 & 220 \\
\hline Lamp Power (W) & 23 & 23 & 18.7 & 18.7 \\
\hline Luminous Flux (Lm) & 1600 & 1600 & 1600 & 1600 \\
\hline Color Type & Warm & Cool & Cool & Warm \\
\hline Color Temperature (k) & 2700 & 6500 & 6500 & 4000 \\
\hline Average Lifetime (hrs) & 10000 & 10000 & 25000 & 25000 \\
\hline
\end{tabular}


To see the wavelength and electrical characteristics of the CFLs and LED lamps in different harmonic levels three different conditions of the $\mathrm{THD}_{\mathrm{V}}$ are used in the experiment. All the conditions are taken within the range of TS EN 50160 i.e. $\mathrm{THD}_{\mathrm{V}}$ must not be more than $8 \%$. In condition 1 , the supply voltage is pure sinusoidal with a fundamental frequency of $50 \mathrm{~Hz}$ without any harmonic component. In condition 2, 50\% of the TS EN $50160 \mathrm{THD}_{\mathrm{V}}$ limit is applied. However, for the condition-3, the value of the $\mathrm{THD}_{\mathrm{V}}$ is taken near to the maximum limit of the TS EN 50160. Detail of the applied voltage $\mathrm{THD}_{\mathrm{V}}$ is given in Table 4.

Table 4. Used THD value of the voltage

\begin{tabular}{|c|c|c|c|c|}
\hline \multirow{2}{*}{ Conditions } & \multicolumn{2}{|c|}{ Harmonic Number (h) } & \multirow{2}{*}{$\begin{array}{c}\text { Total Harmonic } \\
\text { Distortion (THD) }\end{array}$} \\
\cline { 2 - 4 } & 5. & 7. & 11. & $0 \%$ \\
\hline Condition 1 & $0 \%$ & $0 \%$ & $0 \%$ & $3.74 \%$ \\
\hline Condition 2 & $3 \%$ & $2 \%$ & $1 \%$ & $7.87 \%$ \\
\hline Condition 3 & $6 \%$ & $5 \%$ & $1 \%$ & \\
\hline
\end{tabular}

\subsection{Current Harmonic measurement procedure}

As listed in table 3 and table 4; four different lamps are tested for three different conditions. Lamps have same luminous flux. The power consumption of LED lamps is approximately 19W and Compact Fluorescent Lamp is $23 \mathrm{~W}$. All the conditions have been tested at $220 \mathrm{~V}$ and $50 \mathrm{~Hz}$ Frequency.

Each lamp is tested 20 times for each condition and average is taken from obtained results to minimize the error and increase the reliability and sensibility of the output. Furthermore, total current harmonic distortion is taken from obtained current waveform by using MATLAB software.

\section{Measurements and Results}

The measurement of Light Intensity and current harmonic distortion are analyzed and discussed in this section.

\subsection{Measurement of Light Intensity}

This section shows the output of light intensity of the lamps measured by using Newport optical spectrometer OSM-100.

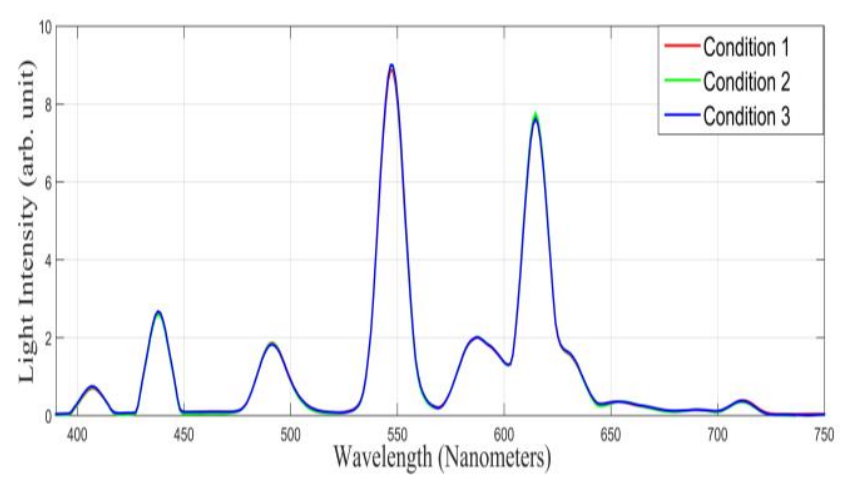

Fig. 4. Light Intensity of CFL-1.

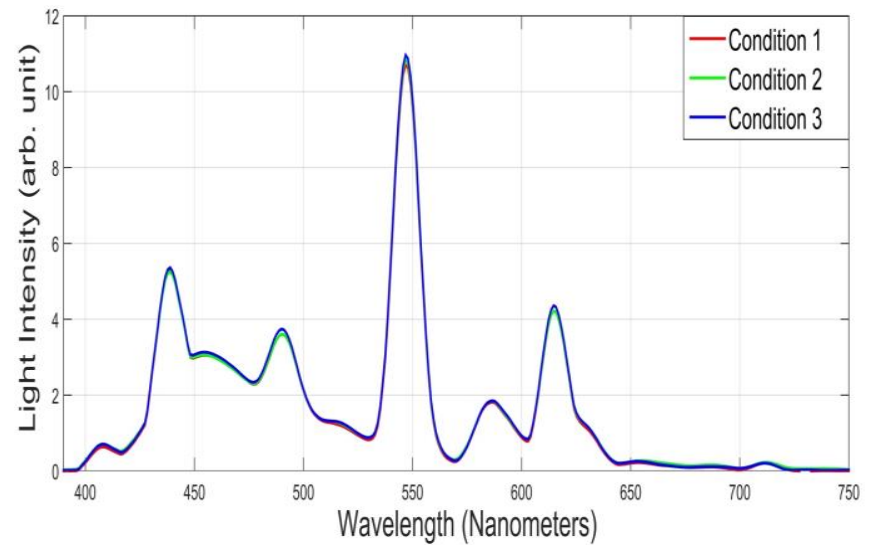

Fig. 5. Light Intensity of CFL-2.

Figure 4 and 5 is showing that the both CFL have the highest peak of light intensity on the wavelength of the 550 $\mathrm{nm}$. However for the second highest peak, both lamps are showing different wavelength, in the case of CFL-1 it lies on the $620 \mathrm{~nm}$ wavelength and for CFL-2 second highest peak lies on the $440 \mathrm{~nm}$.

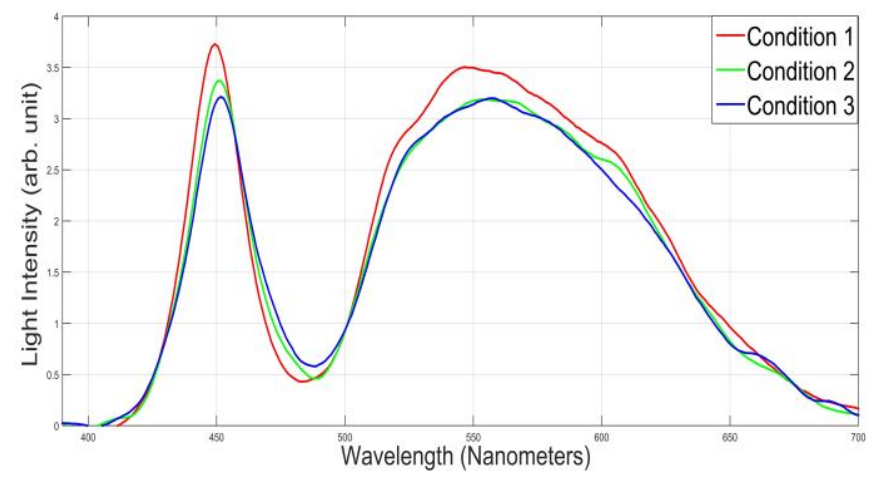

Fig. 6. Light Intensity of LED-1.

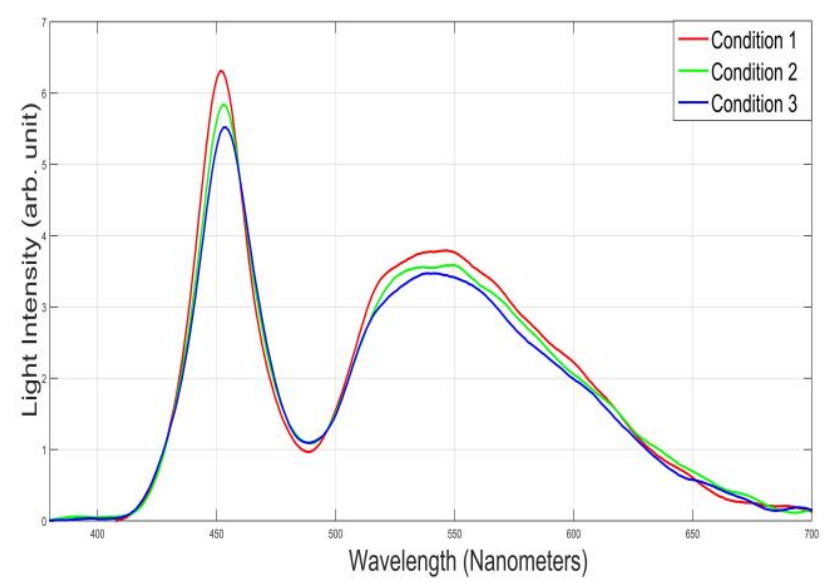

Fig. 7. Light Intensity of LED-2.

Figure 6 and 7 is showing that the both LED have the highest peak of light intensity on the wavelength of the $450 \mathrm{~nm}$. The second highest peak of the light intensity for both of the LED is also same, which lies on the $550 \mathrm{~nm}$.

The experiment shows that light intensity of the CFL is more stable as compared to the light intensity of the LED lamp. Results also show that area of the light intensity of the 
LED lamps is inversely proportional to the total harmonic distortion of voltage and CFL is directly proportional to the value of total harmonic distortion of voltage.

\subsection{Current Harmonic Distortion of lamps}

The Current waveform is used to find the total harmonic distortion of current. It is obtained by performing frequency domain analysis on MATLAB.

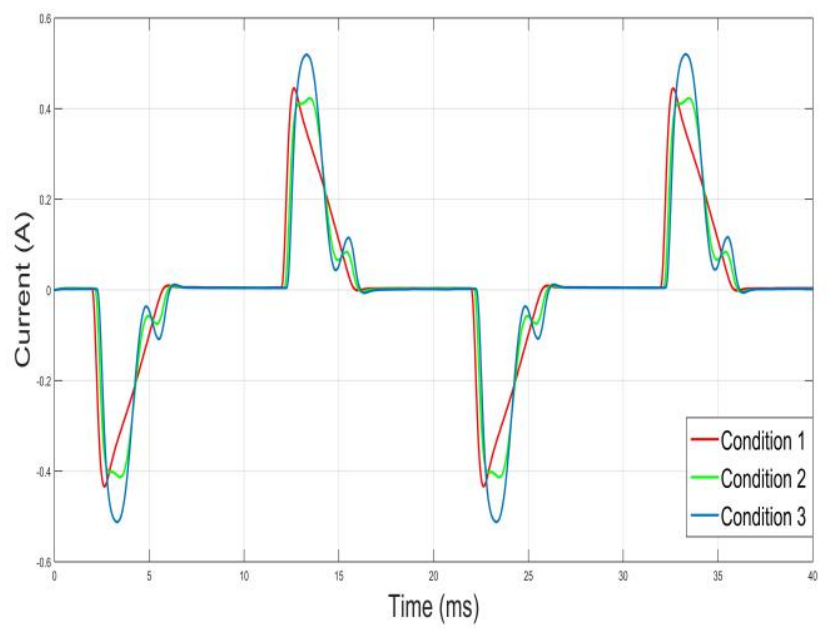

Fig. 8. CFL-1 Current waveform.

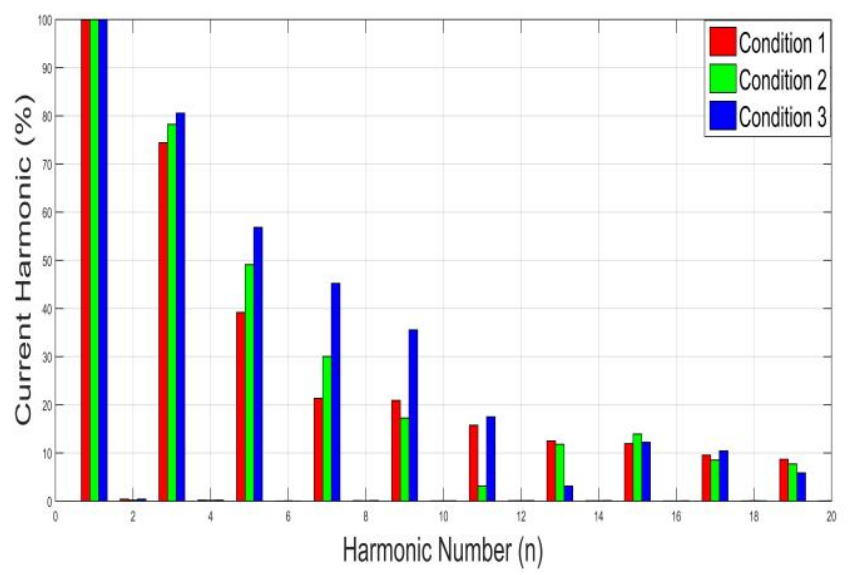

Fig. 9. CFL-1 Harmonic spectrum of current.

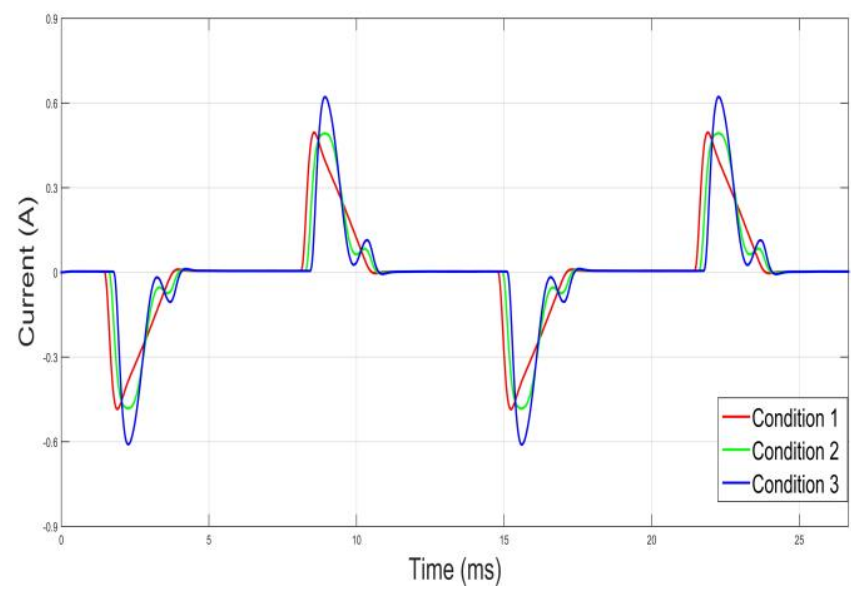

Fig. 10. CFL-2 Current waveform.
Figure 8 and 9 is showing that with the increase in voltage harmonic distortion, current harmonic distortion is also increasing, especially in the $5^{\text {th }}, 7^{\text {th }}$ and $9^{\text {th }}$ harmonic.

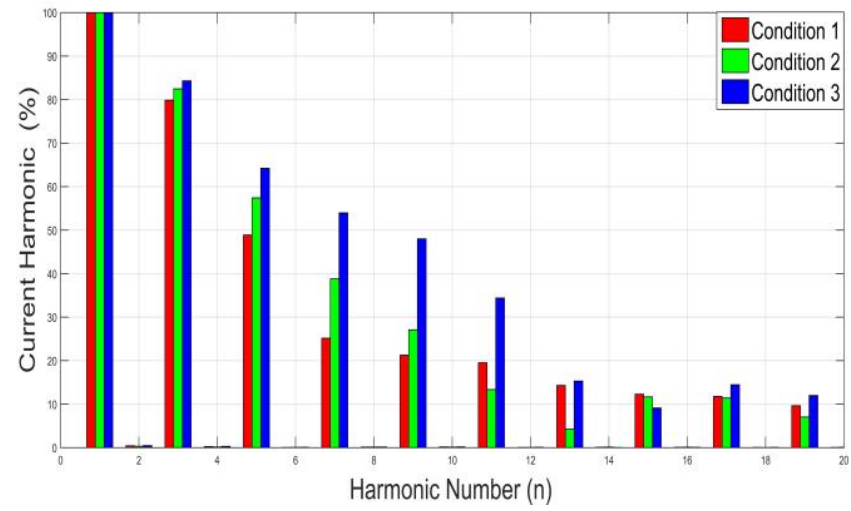

Fig. 11. CFL-2 Harmonic spectrum of current.

Figure 10 and 11 is also showing that with the increase of voltage harmonic distortion, current harmonic distortion also increases. However, results show that $11^{\text {th }}$ harmonic of the CFL-2 is higher as compared to the CFL-1.

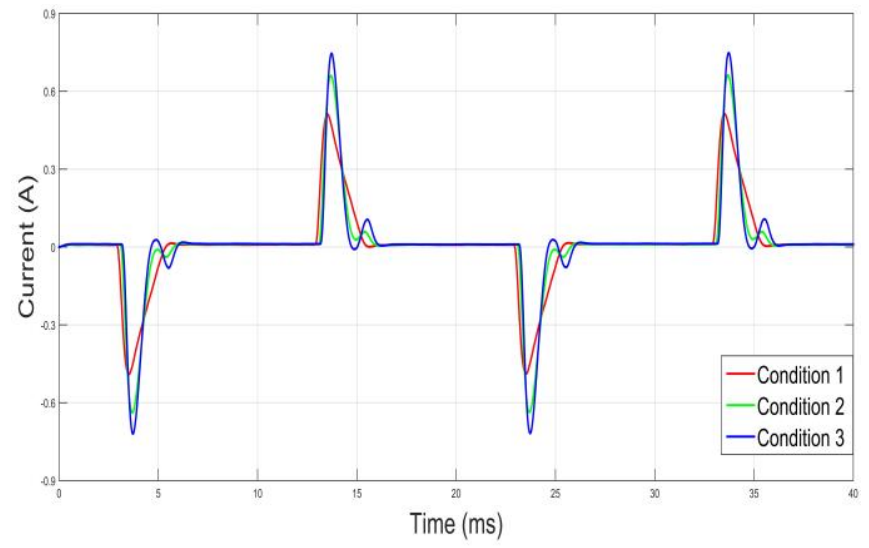

Fig. 12. LED-1 Current waveform.

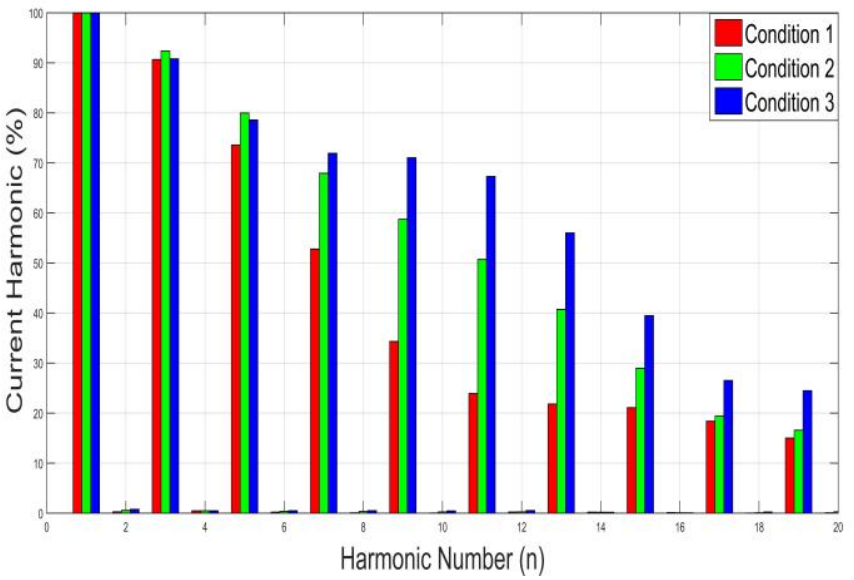

Fig. 13. LED-1 Harmonic spectrum of current.

Figure 12 and 13 is showing the current waveform and harmonic spectrum of the current. Results show that LED is producing more current harmonic distortion; even $11^{\text {th }}, 13^{\text {th }}$ 
and $15^{\text {th }}$ harmonics are producing harmonic distortion in the large quantity.

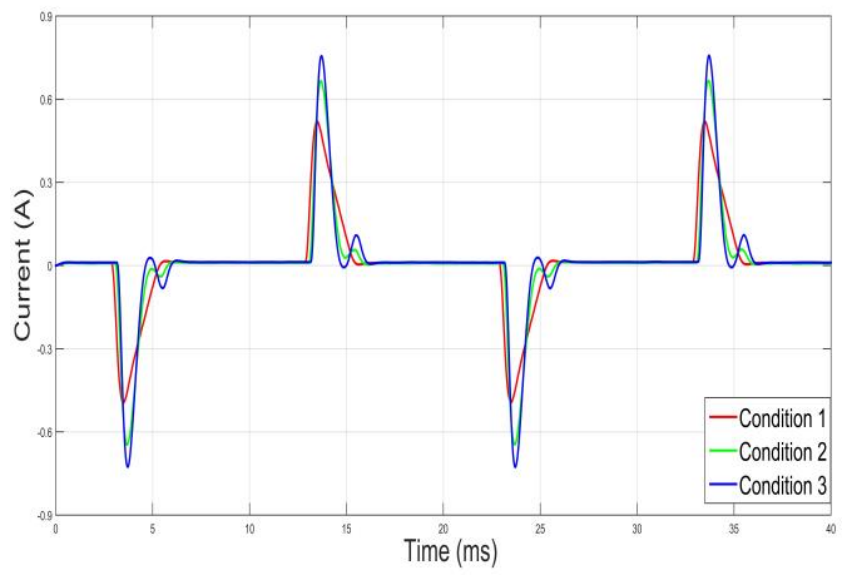

Fig. 14. LED-2 Current waveform.

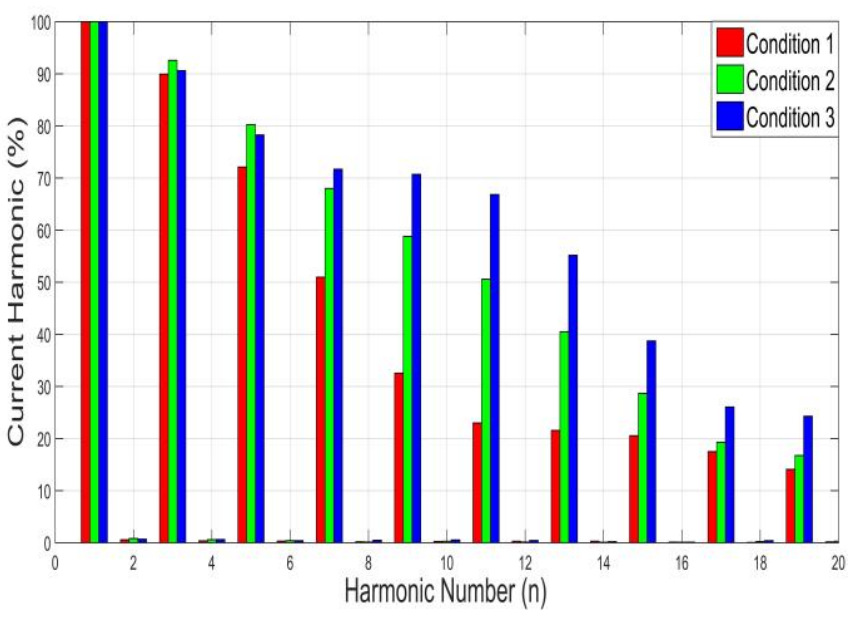

Fig. 15. LED-2 Harmonic spectrum of current.

Figure 15 and 16 are showing the current waveform and harmonic spectrum of the current of the LED-2. Results show that the effect of the voltage harmonic distortion on the LED-2 is same as LED-1.

Table 5 is showing the measured value of the lamps. Results show that all the lamps are producing non-sinusoidal waveform, indicating that lamps are producing harmonics into the power system. For each lamp, $\mathrm{THD}_{\mathrm{I}}$ is increasing with the increase in $\mathrm{THD}_{\mathrm{V}}$. Total current harmonic distortions for both lamps are presented in Table 5. As shown in Table 5 just the first condition of CFL- 1 produced $\mathrm{THD}_{\mathrm{I}}$ value less than 100, whereas all other tested conditions produced $\mathrm{THD}_{\mathrm{I}}$ value greater than 100.

These both lamps are producing high levels of harmonic distortion and these values are not acceptable according to the IEC 61000-3-2 standard. Furthermore, results are showing that LED is producing more harmonic current as compared to the CFL lamp.

Change in $\mathrm{THD}_{\mathrm{I}}$ in cool color type LED lamp and warm color type LED lamp is approximately same for each condition. However cool color type CFL lamp produces more $\mathrm{THD}_{\mathrm{I}}$ as compared to the warm color type CFL lamp.

Table 5 is also showing light intensity area of the CFL and LED lamps with different conditions. Results show that area of the CFL is directly proportional to the harmonic voltages, however, light intensity area of the LED lamp is decreasing with the increased in harmonic voltages. Results also show that light intensity of the CFL lamps is more stable as compared to the LED lamps.

Table 5. Measured Values of the lamps

\begin{tabular}{|c|c|c|c|c|c|c|c|c|c|}
\hline \multirow[b]{2}{*}{ Lamp } & \multirow[b]{2}{*}{ Condition } & \multicolumn{4}{|c|}{ Voltage } & \multicolumn{3}{|c|}{ Current } & \multirow[b]{2}{*}{$\begin{array}{c}\text { Area of the } \\
\text { light } \\
\text { intensity }\end{array}$} \\
\hline & & $\begin{array}{c}\text { RMS } \\
\text { (V) }\end{array}$ & $\begin{array}{l}\text { THD } \\
\text { (\%) }\end{array}$ & $\begin{array}{c}\text { Fundamental } \\
\text { (V) }\end{array}$ & $\begin{array}{l}\text { RMS Value of } \\
\text { the voltage } \\
\text { harmonics } \\
\text { (V) }\end{array}$ & $\begin{array}{c}\text { THD } \\
\text { (\%) }\end{array}$ & $\begin{array}{c}\text { Fundamental } \\
\text { RMS current } \\
\text { (mA) }\end{array}$ & $\begin{array}{l}\text { RMS Value of } \\
\text { the Current } \\
\text { harmonics } \\
\text { (mA) }\end{array}$ & \\
\hline \multirow{3}{*}{ CFL-1 } & 1 & 220 & 0.76 & 215.9 & 1.6 & 94.52 & 125.4 & 118.5 & 400 \\
\hline & 2 & 220 & 3.35 & 216 & 7.2 & 102.17 & 120.2 & 122.8 & 402 \\
\hline & 3 & 220 & 7.53 & 215.4 & 16.2 & 117.7 & 117.3 & 138 & 410 \\
\hline \multirow{3}{*}{ CFL-2 } & 1 & 220 & 0.77 & 215.8 & 1.7 & 105.4 & 120.7 & 127.2 & 574 \\
\hline & 2 & 220 & 3.31 & 215.8 & 7.2 & 114.4 & 118.8 & 135.9 & 591.2 \\
\hline & 3 & 220 & 7.56 & 215.4 & 16.3 & 136.5 & 112.2 & 153.2 & 595.3 \\
\hline \multirow{3}{*}{ LED-1 } & 1 & 220 & 0.75 & 215.9 & 1.6 & 142.9 & 86.7 & 123.7 & 529 \\
\hline & 2 & 220 & 3.32 & 215.9 & 7.2 & 172.8 & 86.2 & 149 & 497 \\
\hline & 3 & 220 & 7.51 & 215.1 & 16.2 & 193.3 & 83.5 & 161.4 & 496 \\
\hline \multirow{3}{*}{ LED-2 } & 1 & 220 & 0.73 & 215.9 & 1.6 & 139.8 & 89.9 & 125.7 & 599.8 \\
\hline & 2 & 220 & 3.3 & 215.7 & 7.1 & 172.96 & 87.2 & 150.8 & 587.7 \\
\hline & 3 & 220 & 7.52 & 215.2 & 16.2 & 192.08 & 85.3 & 163.9 & 562.8 \\
\hline
\end{tabular}




\section{Conclusion}

In this study, light efficiency and electrical characters of the compact fluorescent lamps and LED lamps are investigated under different voltage harmonic levels. Experiments were carried out on a number of lamps in a laboratory environment. Experiments have shown that CFL and LED lamps are a serious source of harmonic distortion. It has been observed that the current harmonics of the LED lamps have increased significantly as the harmonic components are added to the supply source. Furthermore, wavelength characters of the CFL and LED lamps are also investigated. It is seen that under the distorted voltage source CFL and LED lamps also affects the light wavelength of the lamp. The features of the lamps are also important factor as result shows that warm color type lamps produce fewer harmonic as compare to the cool color type lamps.

\section{Acknowledgements}

The authors are grateful to the PELSAN Turkey for providing equipment and technical support.

\section{References}

[1] N. Armaroli, and V. Balzani, Towards an electricitypowered world: Energy and Environmental Science 4, pp 3193-3222, 2011.

[2] C. DiLouie, Advanced Lighting Controls: Energy Savings, Productivity, Technology and Applications, The Fairmont Press, Inc., 2006.

[3] B.J. Huang, P.C. Hsu, M.S. Wu and C.W. Tang, "Study of system dynamics model and control of a high-power LED lighting luminaire", Energy, Vol. 32, No. 11,pp 2187-2198, 2007.

[4] S. Uddin, H. Shareef, and A. Mohamed. "Power quality performance of energy-efficient low-wattage LED lamps", Measurement, Vol.46, No.10, pp 3783-3795, 2013.

[5] Matvoz D., and M. Maksic. “ Impact of compact fluorescent lamps on the electric power network ",In Harmonics and Quality of Power, ICHQP,pp 1-6, 13th International Conference IEEE, 2008.

[6] A. Gil-de-Castro, S. K. Ronnberg, M. H. Bollen and A. Moreno-Munoz, "Harmonics from household equipment and different lamp technologies", Compatibility and Power Electronics 8th International Conference, pp. 1-6, 2013.

[7] R.M Remy, R. K. Rayudu, M. S. Witherden, and E. M. Lai, "Power quality indices of compact fluorescent lamps for residential use-A new zealand study", TENCON 2010 IEEE Region 10 Conference, pp. 647-652, 2010.

[8] S. Elphick, P. Ciufo and S. Perera, "The electrical performance of modern compact fluorescent lamps", Australian Journal of Electrical and Electronics Engineering, vol. 7, pp. 43-51, 2010.
[9] S. K Rönnberg, M. H. J. Bollen, and M. Wahlberg, "Harmonic emission before and after changing to LED and CFL-Part I: Laboratory measurements for a domestic customer", 14th International Conference Harmonics and Quality of Power, pp. 1-7, 2010.

[10] C. Jettanasen and C. Pothisarn, "Analytical study of harmonics issued from LED lamp driver", Proceedings of the International Multi Conference of Engineers and Computer Scientists, 2014.

[11] V. Balzani, G. Bergamini, P. Ceroni, Light, “A Very Peculiar Reactant and Product", Angewandte Chemie International, Vol. 54, No. 39, pp 11320-11337, 2015.

[12] V. Cuk, J.F.G. Cobben, W.L. Kling, R.B. Timens, "An analysis of diversity factors applied to harmonic emission limits for energy saving lamps", Proceeding 14th International Conference on Harmonics and Quality of Power, Italy, pp. 1-6, 2010.

[13] R. Dwyer, A.K. Khan, M. McGranaghan, L. Tang, R.K. McCluskey, R. Sung, and T. Houy, "Evaluation of harmonic impacts from compact fluorescent lights on distribution systems", IEEE Transaction on Power System, vol. 10 , Issue 4, pp. 1772-1779, 1995.

[14] S. Choi and T. Kim, "Symmetric current-balancing circuit for LED backlight with dimming", IEEE Transaction on Industrial Electron, vol. 59, No. 4, pp. 1698-1707, 2012.

[15] R. R. Verderber, O. C. Morse, and W. R. Alling, "Harmonics from compact fluorescent lamps", IEEE Transaction on Industry Application, vol. 29, No. 3, pp. 670-674, 1993.

[16] F. V. Topalis, “ Efficiency of Energy Saving Lamps and Harmonic Distortion in Distribution System", IEEE Transactions on Power Delivery, vol. 8, No.4, pp. 20382042, Oct.1993.

[17] M. Ponce, A. J. Marinez, J. Correa, M. Cotorogea, and J. Arau, "High- Efficient Integrated Electronic Ballast for Compact Fluorescent Lamps", IEEE Transactions on Power Delivery, vol. 21, No.2, pp. 532542, 2006.

[18] E. Fred Schubert, Light-Emitting Diodes:Cambridge University Press,Ed. 2, pp.278, 2006.

[19] F.D. Wijaya, A. N. Widiastuti, and Z.F. Wibowo, "Pengaruh Beban Harmonik Terhadap Putaran Piringan KWh Meter Induksi", CITEE. Indonesia: Department Of Electrical Engineering and Information Tech.,UGM 124, 2011.

[20] Rana A.J., M. Ai-Dabbagh, ,A. Muhammad. "Impact of compact fluorescent lamp on power quality", Australasian Universities Power Engineering Conference, pp.1-5, 2008.

[21] N. Charles , J. Nderu, and L. Ngoo. “ Effects of Compact Fluorescence Light (CFL) Bulbs on Power Quality", Journal of Energy Technologies and Policy,Vol. 2 , Issue 3, pp. 2224-3232, 2012. 
INTERNATIONAL JOURNAL Of ENGINEERING TECHNOLOGIES-IJET

Kamran Dawood et al., Vol.3, No.1, 2017

[22] A.M. Blanco, R. Stiegler, and J. Meyer, "Power quality disturbances caused by modern lighting equipment (CFL and LED)", PowerTech IEEE Grenoble, pp. 1-6, 2013.

[23] Blanco A.M., Parra E.E.,"Effects of High Penetration of CFLs and LEDs on the Distribution

Networks", 14th International Conference on Harmonics and Quality of Power, pp. 1-5, 2010.

[24] IEC Standard 61000-3-2, Limits for Harmonic Current Emissions (Equipment Input Current $\leq 16 \mathrm{~A}$ Per Phase), Ed. 3.2, 2009. 